\title{
Challenges and Countermeasures of Network Security Law Enforcement
}

\author{
Xu Wei ${ }^{1}$, Zhang Tianchang ${ }^{2}$ \\ ${ }^{1}$ Department of Information Technology, Hubei University of Police, Hubei, China, 430034 \\ ${ }^{1}$ Hubei Cooperative Innovation Center for Electronic Data Forensics, Wuhan, Hubei, China, 430034 \\ ${ }^{2}$ Department of Information Technology, Hubei University of Police, Wuhan, Hubei, China, 430034
}

Keywords: network security; law enforcement; challenges and countermeasures

\begin{abstract}
With the rapid development of the Internet, there are more and more illegal crimes on the Internet. In order to comply with the development of the times and meet the challenge of law enforcement, the requirements for the enforcement of network security enforcement are increasingly urgent. This paper first elaborates the connotation and characteristics of network security law enforcement. Secondly, it analyzes the challenges faced by current network law enforcement. Finally, it points out the strategies for enforcing network security law enforcement.
\end{abstract}

\section{Introduction}

China has become the first country in the use of the Internet, and the computer and information network has become an important assistant to our country's economy and important infrastructure, and it has been widely used in various fields [1]. Network law enforcement is the key to realizing the legalization of networkspace, as well as the fundamental guarantee for maintaining network security and network order. Compared with the traditional law enforcement, the illegal subjects, illegal means and illegal consequences of network law enforcement are quite different. In the existing law enforcement, network law enforcement does not play a role in restraining network crimes, maintaining network order and ensuring the legitimate rights and interests of Internet users, and is basically in the state of law enforcement. Therefore, it is an important task for the government to govern the network under the rule of law and how to regulate network order through continuous and effective network law enforcement behavior, to combat network crime and to safeguard the rights and interests of Internet users and Internet security.

\section{The Connotation and Characteristics of Network Law Enforcement}

\subsection{The connotation of network law enforcement}

Administrative law enforcement refers to the management of the society based on statutory authority and statutory duty, and the act of affecting the rights and obligations of the administrative counterpart in accordance with the law. In the internet era, human society no longer refers purely to the real society. Therefore, in order to effectively regulate the network society and maintain the normal order of the network society, administrative law enforcement must extend to the network society, that is, network law enforcement. The law enforcement means that the law enforcement subject, based on the basic law of network development, is based on the legal authority and statutory duty to contain the network crime, safeguard the rights and interests of the network users, maintain the network order and network security, and make the actions and activities that affect the rights and obligations of the relative persons in law enforcement according to law. The network law enforcement is a kind of administrative act, which has legal and national force, the subject of network law enforcement refers to the administrative organs authorized by the law, the object is the network service provider and the network user, the network law enforcement mode includes administrative inspection, administrative penalty, administrative reward, administrative compulsory, administrative adjudication and so on. Administration based on law is the core of network law enforcement, which 
requires network law enforcement agencies to implement enforcement power in accordance with network laws during the process of administrative law enforcement.

\subsection{The characteristics of network law enforcement}

The broader nature of network law enforcement subjects refers to the comparison between network law enforcement and real law enforcement subjects, it is not separate department law enforcement and single area law enforcement, but at least the cooperation of two or more departments and regions in law enforcement, which mainly manifested in the wide distribution of law enforcement subjects, and involving a wide range of departments [2]. The network is open and has no boundaries, so network violations often involve multiple regions or even many countries. The rapid spread of the Internet also increases the speed of development of the consequences of illegal crimes. Therefore, network law enforcement is not a law enforcement of a single department, but wide-ranging, multi-sector, multi-regional cooperation law enforcement. Moreover, the feature of network law enforcement has directly strengthened law enforcement cooperation and exchange among various departments and regions, and has broken down the administrative bureaucratic system that separates and separates self-enclosed, which is conducive to deepening the reform of the administrative system.

Compared with the real society, internet society is essentially a virtual society. Network law enforcement is an administrative act in law enforcement activities in the network virtual society, so unlike the reality of law enforcement, the network enforcement environment is in the physical existence of a real society for law enforcement activities. In the virtual society, any network organization and Internet users can interact with law enforcement personnel and law enforcement departments through network media, such as online reporting of illegal and criminal behavior, and online provision of electronic evidence. Similarly, network law enforcement personnel also perform law enforcement functions through network media, implement law enforcement power, obtain and store relevant law enforcement information through network, and communicate with other law enforcement departments. In short, all network law enforcement activities and law enforcement actions can be carried out through the network, so the network enforcement environment is quite fictitious.

\section{Challenges Encountered in the Law Enforcement of Network Security}

\subsection{Ascription of geographical law enforcement}

In the network society, illegal and criminal behaviors are virtual, which do not possess on-site features, and they spread across a wide range because of the network's non-boundary nature. The place where the activity occurs, the place where the result takes place and the place of residence are usually different. Therefore, the principle of geographical enforcement of real law enforcement cannot be applied to network law enforcement. Under the existing administrative system in our country, for the problems concerning the division and ownership of enforcement powers in multiple regions in the network society, it is impossible to copy the systems and mechanisms related to the actual law enforcement. There is no legal guarantee, benefit-sharing system, or coordinated enforcement mechanism, and disputes over the ownership of law enforcement rights are relatively controversial in network law enforcement, cooperation law enforcement and law enforcement are weak, and there is insufficient stress on the issue of network law violations.

\subsection{Low professional ability in law enforcement}

Law enforcement professional ability is mainly manifested in technical ability and professional quality. First of all, network law enforcement has high technical requirements for law enforcement personnel, who should not only be familiar with the Internet, but also be proficient in various network system knowledge and various network technologies to conduct network information data analysis and network tracking of networkcriminals, thereby improving the level of network law enforcement. Secondly, network law enforcement requires higher professional quality of law enforcement officers. On the one hand, network law enforcement personnel should have a higher quality of rule of law. The 
network law enforcement is different from the actual law enforcement, the network law enforcement has the virtuality and the network legal system is incomplete. Network law enforcement is virtual and the network legal system is incomplete. Under such circumstances, law enforcement personnel should possess strong legal knowledge, strong legal application skills, and high legal quality.

\subsection{Legal dilemma}

A sound network legal system is the decisive factor to enhance the effectiveness of network law enforcement. At present, China lacks the basic law of the network, and most of the network focus areas are blank in legislation, the low legal effectiveness of the department, policy documents, and law enforcement lack of supporting measures. The current weak situation in network legislation makes China's network law enforcement facing problems such as inability to comply, lack of law and conflict of laws.

\section{Countermeasures of Network Security Law Enforcement}

\subsection{Establish the principle of regional ownership of enforcement power}

First of all, using the principle of victimization, which refers to the determination of the right of network law enforcement based on the principle of victimization or infringement by network criminal acts. Compared with the behavior and result of the network crime, the victim has more certainty and feasibility, and it is more convenient for the network law enforcement personnel to carry out the law enforcement activities [3]. Secondly, the principle of priority is supplemented by the principle of law enforcement, which can reduce the dispute about the ownership of law enforcement to the maximum extent, reduce the cost of law enforcement, save the time of law enforcement, improve the enthusiasm of law enforcement, and avoid repeated law enforcement. Finally, it is supplemented by the principle of consultation. There are differences and disputes about the law enforcement power of the network. In order to effectively avoid the conflict between the law enforcement bodies, we should strengthen cooperation and consultation on the basis of the principle of victimization and the principle of priority law enforcement, and have the consciousness of the overall situation on the basis of maintaining the public interests of the network society, and could make certain concessions and compromises.

\subsection{Provide evidence guarantee for network law enforcement}

E-evidence is a key element in verifying network criminal suspects, identifying the facts of the case, and sanctioning criminal offenses. Therefore, it is imperative to enhance the effectiveness of electronic evidence from the technical and institutional levels, and provide guarantees for the smooth implementation of network law enforcement. The network law enforcement departments should follow and utilize the characteristics of the Internet data integration, establish the network information data platform and the network information database, establish the data linkage mechanism, strengthen the sharing of interdepartmental network information data, and achieve seamless docking in the premise of ensuring the security of the network information database, and improve the acquisition efficiency of electronic evidence. In addition, the burden of proof of network service providers should be increased appropriately. As a master of network social data information, network service providers have an incomparable advantage over other network lines, whether it is in the technology of obtaining electronic evidence or in the convenience. Therefore, in the system level, it is necessary to appropriately increase the burden of proof of network service providers, to do a good job in the related electronic data backup and data protection system, and to fulfill the burden of proof.

\subsection{Strengthen the construction of law enforcement teams}

Network law enforcement personnel, as direct implementers of network laws, are important guarantees for improving the level of network law enforcement. Qualified network law enforcement personnel should be composite talents with professional skills and law enforcement professional capabilities [4], that is, solid computer information technology and network technology, as well as legal literacy and professional competence. Therefore, the construction of law enforcement teams 
should be strengthened from the following aspects. First of all, in the recruitment of network law enforcement personnel, we should pay attention to the balanced distribution of personnel structure. Secondly, establish specialized internal training institutions. Network law enforcement inevitably appears many new problems and new phenomena beyond the scope of the existing theory in practice. Therefore, through training institutions to learn the successful experience of network law enforcement and failure lessons is very helpful to cultivate enforcement teams.

\subsection{Improve the network legal system}

A sound network legal system is a necessary prerequisite and an important basis for the smooth progress of network law enforcement. On the contrary, the lack of network laws will result in weak enforcement and lack of authority and standardization. Therefore, we should strengthen network legislation and improve the network legal system. Second, we should follow the law of the development of the network society, and establish a network of legal thinking. Strengthen the implementation and operability of existing network laws, and issue corresponding judicial interpretations and enforcement measures to provide legal guarantees for network law enforcement.

\section{Summary}

Most of the problems encountered in the enforcement of network security are caused by the incomplete legal system of the network security and the lack of legal resources. Therefore, firstly, it should first rationalize the power of law enforcement and provide institutional guarantees for network law enforcement. Second, it should improve the effectiveness of electronic evidence and provide evidence for network law enforcement. The third is to strengthen the construction of law enforcement teams and provide human security for network law enforcement. Finally, we should improve the network legal system to provide legal protection for network law enforcement.

\section{References}

[1] Guo Zhilong. The Network Security Content System and the Orientation of Legal Resources[J]. Law Forum, 2014, p.39

[2] Wang Zhe. Singapore Network Security Bureau was Formally Established to Deal with Network Security Threats [J]. Information Security and Communication Security, 2015, p.41

[3] Zhou Qingshan. On the Overall Construction of Network Legal System[J]. Hebei Legal Science,2014(8), p.10

[4] Xu Hao, Zhu Jin, The Challenge of Network Development to Public Security Work [J]. Public Security Research, 2009, p.42 